\title{
Mini review on the design of axial type eddy current braking technology
}

\author{
H.T. Waloyo ${ }^{1}$, Ubaidillah ${ }^{2}$, D.D.D.P. Tjahjana ${ }^{3}$, M. Nizam ${ }^{4}$, T. Koga ${ }^{5}$ \\ 1,2,3 Mechanical Engineering Department, Universitas Sebelas Maret, Indonesia \\ ${ }^{2,3,4}$ National Center for Sustainable Transportation Technology (NCSTT), Indonesia \\ ${ }^{4}$ Electrical Engineering Department, Universitas Sebelas Maret, Indonesia \\ ${ }^{5}$ Yamaguchi University, Ube Campus, Yamaguchi Perfecture, Japan
}

\section{Article Info \\ Article history: \\ Keywords: \\ Axial type \\ Braking \\ Eddy current \\ Performance}

Received Mar 27, 2019

Revised Jun 30, 2019

Accepted Jul 10, 2019

\begin{abstract}
Eddy Current Brake (ECB) is a type of electric braking that uses eddy current to produce braking forces. This article delivers a solid review of the design of Axial ECB, which is very promising for an alternative braking system. Several types of axial ECB are classified and named as a single disk, double disk, and unipolar model. The classification of axial ECB is based on the design of coil placement, which induces axial area of the disk as well as the electromagnet source. A potential issue for the development of axial ECB is also discussed to explore the braking performance improvement of the axial type ECB. It was highlighted that research on how to change the direction of magnetic field vectors by changing the shape of the pole-shoe on the electromagnetic ECB in axial type has not been widely studied. Therefore, this issue would be interesting for future investigation.
\end{abstract}

Copyright (C) 2019 Institute of Advanced Engineering and Science. All rights reserved.

\section{Corresponding Author:}

D.D.D.P. Tjahjana,

Mechanical Engineering Department,

Universitas SebelasMaret,

J1. Ir. Sutami 36 A, Kentingan, Surakarta, Central Java, Indonesia, 57126.

Email: ddanardono@staff.uns.ac.id

\section{INTRODUCTION}

Braking system has been currently developing in accordance to the fast grow of vehicle technology. Since the absence of engine brake in pure electric vehicles, another option to support brake is using electric type braking system $[1,2]$. For example, the use of eddy current brake (ECB) has been becoming alternatives for replacing engine brake through regenerative system [3]. Basically, electric braking system has noncontact braking in which it is vallue added compared to the conventional hydraulic system. In regenerative braking, this system converts the inertial forces produced by vehicle movement to electrical energy [4]. By using a battery management system, the electrical energy was then stored in the battery for another utility [5]. In accordance with the advantages of mechanical and electrical braking systems, researchers combined all those types to get better performances [6].

The ECB is widely used in railroad vehicles application. It has been turning into the market which was pioneered by ICE3 for braking systems on trains [7]. So far, the use of ECB is mainly for the high-speed vehicle because the velocity aspect strongly influences the main characteristic. There is a high need to apply the ECB to low speed of vehicle. To improve ECB performance, some researcher pays more attention to its design (materials and structure) than control strategy [8]. Regarding ECB materials, there are several discussions put forward by the author, including the effect of rotor materials to braking torque [9]; a combination of two different material in the form of adding "back iron" structure [10]; as well as the coating on the conductor [11]. Moreover, regarding ECB structure, some efforts were undertaken to improve the magnetic performance such as surface conductor modification [12] and improvement of the magnetic circuit 
[13]. For instances, in the way to maximize flux density, permanent magnet Hallbach configuration was adopted on ECB permanent magnet $[14,15]$.

Researchers pay more attention to the development of the ECB which can be seen the number of publications dealing with the design and improvement of ECB increase. The type of ECB that is widely applied for braking is the Axial ECB. A journal review of ECB axial development is needed to identify the techniques that have been used before briefly. No one has tried to collect literature review on the design and development of the axial ECB. To the best of author knowledge, there are only a few authors who proposed review articles to summarize the current research in ECB development. Thompson [16] conducted a review on the application of $\mathrm{NdFeB}$ to various application; one of them is the ECB. Krishna and Kumar [17] reviewed the ECB system in general and its basic working principle. This paper [17] give short describes how ECB works and improvement. Singh et al. [18] conducted a review with the main topic on the design overview and use of the ECB system in various application. However, the information within the report was not complete due to the proceeding limitation.

Along with the rise in the number of publications in this area, it is necessary to establish a comprehensive review which contains a complete highlight of those publications. This paper presents detailed reports of previous studies related to axial ECB design development. In this journal review, axial ECBs are grouped into a single disc, double disc, and unipolar types. The discussion on axial ECB is carried out by explaining the development of the design structure, then modifying the magnetic field to determine the performance. In this paper, the basic principles of the ECB would be explained, followed by discussions on the axial ECB classification, improvement, and future highlight.

\section{WORKING PRINCIPLE}

Eddy current is the induced current that occurs due to the magnetic field change in a conductor. The magnetic field will produce an eddy current loop pair and the current loop will produce an inductive magnetic field. Based on the relative motion of the conductor, in the edge will produce an induction magnetic field with same direction of the main magnetic field. The same direction of magnetic flux will cause repulsion. While at the rear, a induction magnetic field will be formed opposite to the main magnetic field. The attractive force will occur on the back side. Both forces will provide a resultant effect opposite to the direction of magnetic field motion. Smythe [19] introduced the phenomenon, which firstly investigated eddy current on a disc.

The main energy source in ECB comes magnet or electromagnet. In the permanent magnet (PM) ECB, magnetic flux density became constant in all the time. PM ECB braking torque control can be done by changing the width of the air gap [20] or providing a magnetic barrier [21]. On the other hand, the electromagnetic-based ECB performance depends on electrical power and coil configuration. The amount of current in direct current (DC), is equal to the magnetic field. In the use of alternating current (AC) electricity, the frequency setting and current-signal form are those that affect the braking performance.

One of the essential phenomena in the ECB is skin effect. In this situation, the amount of Eddy current decreases at a certain distance far from the surface. The depth of skin effect strongly depends on the speed, while speed increase the skin effect will drop [22]. Schieber [23] found the influence of skin effect was not significant at thin plate disk ECB. In the other hand, Singh [24] investigated thick plates and found the skin effect greatly affected the braking torque at high speed.

\section{AXIAL ECB TYPES}

The axial model of Eddy current brake has the main characteristic of a disc-shaped conductor, while the design of a magnetic field source can be a disk or single. The axial model ECB also called a Disc ECB. The magnetic field source can be electromagnets or permanent magnets. A single axial ECB uses a magnetic field source that is designed in the form of a single disc. The magnetic field source is placed parallel and facing the conductor. To improve the energy efficiency, the model is set in a double axial ECB. The magnetic field source is flanked by two conductor discs. Using this design, the conductor can capture the overall magnetic flux of the two magnetic poles. The double axial ECB can be set by placing a magnetic field source on both sides of conductor disk. With this arrangement, a large torque will be obtained. A unipolar structure is used to simplify the design but still produce a large braking force. The unipolar form is made by using a magnetic field source that forms a single loop.

\subsection{Single axial ECB}

Single axial ECB consists of a conductor disc and a magnetic field source disc. There is an air gap that separates the two discs with a certain width, as shown in Figure 1. The magnetic flux density in the air 
gap is directly related to the braking torque. Thus, to increase flux magnetic can be done by arranging the permanent magnet pole in the hallbach arrangement [14], [15] or by combining electromagnets and permanent magnets in one pole [13], [21]. Whereas in the conductor section, where the induction magnetic field occurs, the use of materials and designs influence braking torque. The type of conductor material affects the braking characteristics at a specific speed range [25]. The combination of Ferro and non-ferrous metals as a conductor can improve braking performance [25-27]. While on the design side, changes in the shape or size of a conductor will influence the magnetic field and eddy currents [28], [29].

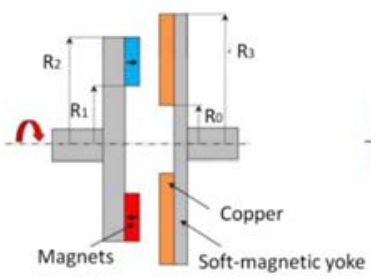

(a)

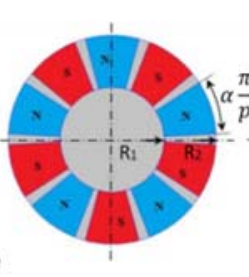

(b)

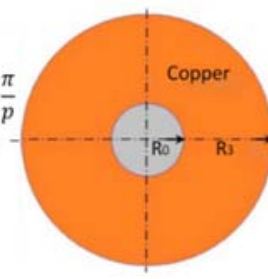

(c)

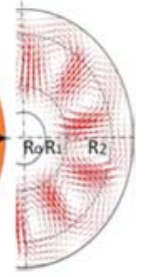

(d)

Figure 1. Single axial ECB (a) configuration (b) magnet (c) conductor (d) eddy current [28]

Increasing the magnetic flux density in the air gap can be carried out by directing the magnetic flux to the conductor. By using the hallbach method, the orientation of the magnetic flux will concentrate to the conductor disc [14]. Figure 2a shows the hallbach array for a permanent magnet. Dai [15] made hallbach arrangement design by using three permanent magnets in each segment. Optimal braking is obtained at 55 degrees and 0.4 ratios of the mid-magnet pole arc to the pole pitch. Wang [14] examined the permanent polar arrangement with the Quasi-hallbach model, which produced a higher magnetic field density than conventional methods. The results showed that the need for back iron PM with the quasi hallbach is thinner than the traditional to obtain the same magnetic field density.

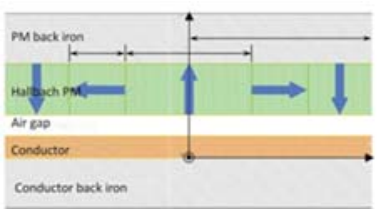

(a)

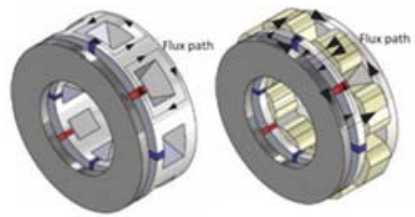

(c)

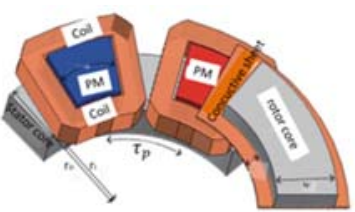

(b)

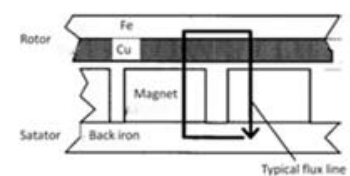

(d)

Figure 2. Single Axial ECB (a) Hallbach array [14] (b) magnetic core [13]

(c) Parallel hybrid [21] (d) Hybrid conductor [25]

The use of hybrid magnetic field sources is another way to increase the magnetic field density in the air gap. Yazdanpanah [13] used two magnetic field sources simultaneously by making a permanent magnet as a coil core, as shown in figure $2 \mathrm{~b}$. This design produces braking torque higher than conventional ECB at the same current. This design has drawbacks, there is still a braking force at the time no current flow. As a design improvement, Gulec [21] proposed design by placing a permanent magnet at the pole shoe gap. The arrangement then forms parallel magnetic circuits, as shown in Figure 2c. Since the permanent magnet is at the end of the coil core, the magnetic field of magnet flows to the coil core at the time no electrified coil. In other hand, permanent magnet increases the strength of the magnetic field when the coil is excited.

Int J Pow Elec \& Dri Syst Vol. 10, No. 4, Dec 2019 : 2198 - 2205 
The type of conductor material with specified properties changes the trend of the braking force curve in speed variation. As reported by Lequesne [25], that the permeability and conductivity of materials significantly affect the braking torque. Braking torque characteristics will be different when the conductor uses magnetic or non-magnetic materials. In the ferromagnetic conductor provides low braking torque at low speeds and gradually rise when the speed increases up to reach the maximum torque. While non-Ferro or aluminum produces high torque at low rates, it will drop after reaching critical speed. Critical speed is a speed when braking torque reaches maximum value.

The use of magnetic and non-magnetic combination will generate better braking torque than single material only. Ferro materials have high permeability so that the induced magnetic field produced is high, but the eddy current produced is low due to higher electrical resistance. Whereas non-ferrous metals have lower electrical resistance so they can produce higher eddy current but inhibit the magnetic fields. Lequesne [25], conducted a study comparing aluminum and copper as non-magnetic materials, which were then combined with a ferromagnetic material, as shown in Figure 2d. From the research, it was found that the combination of copper $(\mathrm{Fe}-\mathrm{Cu})$ produced braking torque with a critical speed lower than Aluminum ( $\mathrm{Fe}-\mathrm{Al})$. By using $\mathrm{Fe}-\mathrm{Cu}$, it can provide better braking than using aluminum and can even save up to $40 \%$ on the use of magnets at low speeds.

The conductor is an ECB part where magnetic flux flows and eddy current forms. Changes in the conductor shape will affect the magnetic flux flow or the eddy current intensity. Razavi [27], conducted a study by making a slot on the copper conductor layer. The use of slots can increase $15 \%$ of the braking torque compared to the plane conductor. Furthermore, the slot is varied by providing a magnetic material core. The calculation found that the use of ferromagnetic, in the slot gap, can increase braking. Based, on the same design, Dai [26], conducted a study by making a model using 3D FEM. The eddy currents that occur are concentrated in copper slots so that the current density becomes high. These findings confirm that the use of copper layer slots affects improving braking torque. Labbe [29], conduct another researche to modify the conductor by adding cooling fins. The addition of fins is intended to maintain braking performance by increasing the cooling rate. In the other hand, giving cooling fins will affect the flow of the magnetic field, as shown in Figure 3. It was found that the fins effect of calculations occurs at low speeds. At high rates, there is no effect of count fins at the estimate.

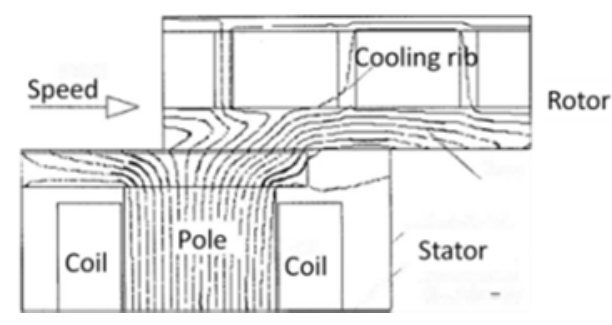

Figure 3. ECB with cooling rib Flux magnet distribution [29]

The ratio of conductor diameter to the magnetic field source will affect the amount of braking torque. Lubin [28], conducted a study by varying conductor size. The conductor diameter is set more extensive than the magnetic disc to provide the space for electrons move. The conductor area that receives the magnetic field and provides force is called the active region. Figure 1d shows the eddy current occurs in the conductor. The larger radius of conductor results in an increase in braking torque. After reaching the optimum size, enlarging the conductor diameter will not increase the braking torque significantly.

\subsection{Unipolar axial ECB}

Unipolar axial ECB consists of conductor disc and looping electromagnetic coil core, as shown in Figure 4a. The unipolar name is referred to the work as written by Schieber [23]. By using unipolar type will minimize magnetic field leakage. The magnetic field from the source is channeled to the conductor via pole shoe. Thus, the use of pole shoe with a certain cross-section affects braking [30]. The magnetic field used comes from DC electricity. The main problem with ECB braking is the amount of braking that is proportional to the vehicle's speed, even at zero speed, there is no braking. To overcome this, AC power is used [31-33]. In the conductor, addition of different metal alloy elements to the conductor produces different performance [34]. 


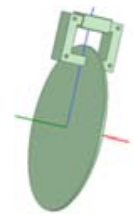

(a)

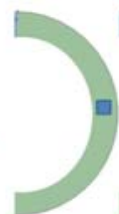

(b)

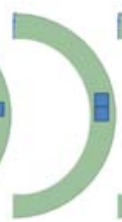

(c)

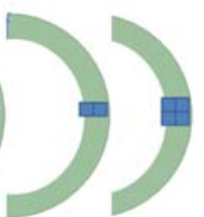

(e)

Figure 4. Unipolar ECB (a) configuration (b) Single magnet. (c) Double magnet tangential.

(d) Double magnet radial. (e) Quad magnet [30]

The braking force on ECB is influenced not only by the magnetic flux density but also the distribution. The cross-section of the Pole Shoe will affect the magnetic field distribution at the conductor. Gosline [30], made a study by comparing several permanent magnets arrangements to represents the pole shoe shape, as shown in Figure 4. Two permanent magnets are arranged in tangential (Figure 4b) and radials (Figure $4 \mathrm{c}$ ). It is found that the tangential arrangement produces higher braking torque than the radial. Then the tangential permanent magnet arrangement is duplicated in a radial direction to form a square, as show Figure 4e. The double magnet arrangement produces an increase in braking torque that is not significant while use double magnet. The conclusion is the tangential method results in higher braking than the radial arrangement.

Electromagnetic type of ECB usually uses DC current to produce a magnetic field. The use of DC current has disadvantage at low speeds. It requires large current flows to provide the required torque. Karakoc [31], conducted a study to increase braking capacity at low speeds by using AC electricity. The AC power used is in the form sawtooth, triangle, and sinus shapes. From the calculation results, good braking performance is obtained from the triangle and sinus shape. Karakoc [32], made improvements to the triangle and sinus signals with optimization using PPA (Pole Projection Area) with GA (Genetic Algorithm) optimization system. In this research, four PPA points were used. With the proper placement of PPA points, a significant increase in braking is obtained. Karakoc [33] also mention that the increase in braking torque due to changes from DC power sources to AC occurs at all speed variations. The improvement at high speeds is wider than at low. AC currents are better than DC currents and get better at high speeds.

Metal alloys conductors with different elements will produce different braking torques. Gaharom [34], made a comparison on aluminum alloy series A16061 and A17075 as a conductor. The differences in alloy elements affect the permeability magnet and electrical resistance. From the data, it was found that A16061 has twice electrical conductivity when compared to A17075. As a result, aluminum A16061 series produces better braking torque than the A17075 series.

\subsection{Double axial ECB}

Double axial ECB is an axial ECB that uses dual magnetic field sources or dual conductors. Figure 5 a shows the use of double magnetic field sources. This configuration is intended to get high braking torque. In the other hand, the use of double conductors is designed to improve efficiency by reducing magnetic flux leak. In another analysis, braking torque depends on the distribution of the magnetic field intensity in the air gap. Permanent magnet configuration affects the distribution of magnetic fields in the air gap. The right approach of magnetic field will provide good accuracy of numerical analysis [35]. On electromagnet ECB, the use of pole shoe will affect the direction of the magnetic field [36]. Modification of magnetic flux on the conductor disc can be done by providing a slot that modifies the direction of the eddy current [37].

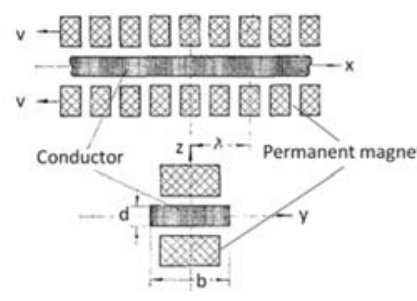

(a)

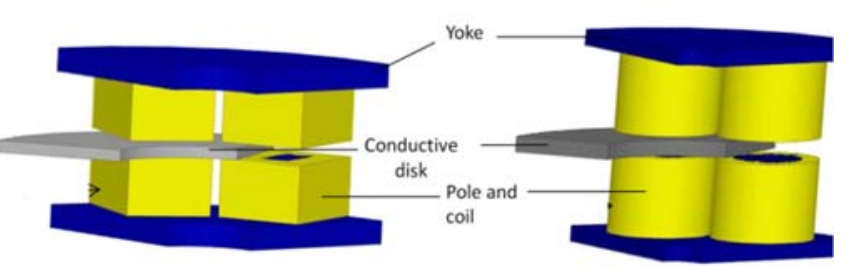

(b)

(c)

Figure 5. Double axial ECB (a) Double permanent magnet configuration [35] (b) Rectangular pole shoe [36] and (c) round pole shoe [36]

Int J Pow Elec \& Dri Syst Vol. 10, No. 4, Dec 2019：2198 - 2205 
The main determining factor of braking torque is the magnetic field density in the air gap, while the profile of magnetic field distribution depends on the number and placement of magnetic sources. Baran [35] research is about the influence of the number of poles. His research was carried out by analyzing the use of two and eight permanent magnet arrangements. By using two magnetic field sources, the magnetic field values directly reach the top at the permanent magnet position. While in the method of eight permanent magnets, a sinusoidal magnetic field profile is obtained. Calculation of braking torque, in mathematical analysis, only uses the maximum value or the average value of the air gap magnetic field. The impact is the calculation results will have a difference with real measurements. The addition of the correction factor turns out to improve the calculation results, thus producing a right level of accuracy. In addition, the shape of the coil core also affects the amount of braking torque produced. Gulbahce [36], compared pole shoes with circular and square shapes, as shown in Figure 5b-5c. And it was found that the square-shaped produces higher braking torque with almost constant critical speed.

In the conductor part, changes in the surface shape will produce different braking. Robert [37], conduct research which added slots on the surface of the conductor, as shown in Figure 6. The study was carried out by comparing braking torque in flat without slots, six slots, and twelve slots. The results showed that giving slot on the surface increased the braking torque. The addition of slot number is not proportional to the increase in braking torque. The addition of doubled slot number only results in a small rise in braking torque. The addition of slots is intended to modify the flow of the induced current to increase current density in certain parts.

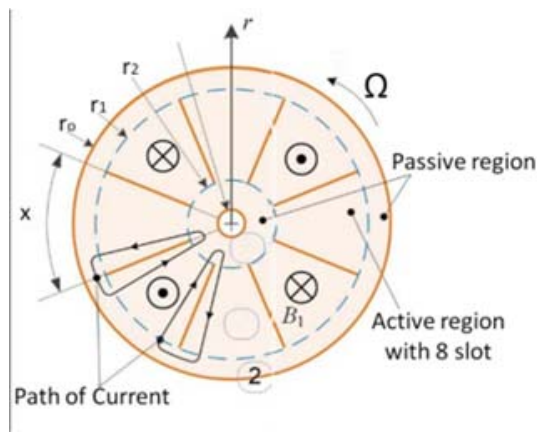

Figur 6. Slotted conductor [37]

\section{FUTURE HIGHLIGHT}

Design factors strongly influence the ECB designing process which aims to produce quality braking system. Some parameters that influence the ECB design include disc thickness, air gap width, type of electric current used, and multiple layer usage. The development of the Axial ECB as support for braking systems or alternative replacements for conventional braking systems has been mentioned in the previous section. The choice of materials for conductors affects braking performance. The main material characteristics that affect the amount of braking torque are permeability and resistivity. By using materials with high permeability, good magnetic performance will be obtained so that the eddy current produced will be even higher. Meanwhile, the low resistivity will reduce the electrical losses so that the magnetic field of the resulted induction becomes more significant, and the ECB's performance can be maximized.

Material with high permeability produces high maximum torque, but the critical speed is also high. The use of this material is less suitable for low-speed braking needs. The use of nonmagnetic conductor material is very suitable for low-speed braking. An effort was carried out to combine these two properties by using two layers. By combining these two materials, improvements will be made to the torque produced and the critical speed of braking. The use of magnetic base material, which is given a thin conductor layer can improve performance. The addition of a thin layer to the conductor will reduce the electrical loss of eddy current. The use of non-magnetic materials is combined with a back iron which functions to flatten the magnetic field so that the eddy current that occurs is also distributed more evenly. From the effort to improve the braking performance by adjusting the properties of materials, no researcher has conducted activities to find material with the required properties, whose permeability is high but with low electrical resistance.

Braking strength is greatly influenced by magnetic field density in the air gap area. The magnetic field polar direction affects the braking torque produced. The influence of the magnetic field direction has been studied in conventional and hallbach arrangements. Each direction of the magnetic field produces 
different braking torques. The direction setting of the magnetic field is only applied to permanent magnets, whereas for electromagnetic studies, there has been no study examining the effectiveness of vector magnetic flux. Setting the direction of magnetic field flux vectors in electromagnetic circuits can be done by adjusting the working frequency and voltage. The use of more than one-line magnetic field sources has not been studied as well. Adjusting the direction of the magnetic field from the magnetic field source can be done to obtain good magnetic field density.

The electromagnetic coil core construction design can still be optimized by using a shoe shape modification. To date, research on the shoe section is limited to the application of thickness and pole pitch. Made the pole shoe surface uneven will increase changes in the magnetic field, thus increasing braking torque [32]. Magnetic fluxes set up to provide increased braking performance is carried out by minimizing magnetic field leakage. Magnetic field leaks can be reduced by using magnetic field directors or magnetic insulators for adjacent poles. With reduced magnetic field leakage, the braking torque obtained will be greater.

\section{CONCLUSION}

It is well known that the ECB has been utilized for various applications. Several improvements have been made by reducing energy losses or increasing braking torque and efficiency. To enhance performance, there needs to be a modification. Changes to basic design are the first step to improving performance. By combining a magnetic field source or modifying a magnetic field source. The shape and conductor material also affect. Magnetic flux is the main source that can be known to increase braking torque. Some things that have not been much of a concern are the use of different disk shapes to increase braking torque. With the increase in braking torque, it is expected that the ECB can be used as the main braking system. Improvements can also be made using changes in the construction of the system. So it is still possible to increase the performance of braking on a more specific type of ECB.

\section{ACKNOWLEDGEMENT}

This work partially supported by the SHERA Project Prime Award: AID-497-A-16-00004, USAID and fully funded by Universitas Sebelas Maret (UNS) through PNBP PU-UNS No. 516/UN27.21/PP/2019.

\section{REFERENCES}

[1] W. A. Salah et al., "Electric vehicle technology impacts on energy," International Journal of Power Electronics and Drive Systems (IJPEDS), vol. 10, no. 1, pp. 1-9, 2019.

[2] U. Ubaidillah, F. Imaduddin, M. Nizam, and S. A. Mazlan, "Response of A Magnetorheologi cal Brake under Inertial Loads," Int. J. Electr. Eng. Informatics, vol. 7, no. 2, pp. 308-322, Jun. 2015.

[3] M. Kavitha, V. Elanangai, S. Jayaprakash, and V. Balasubramanian, "Development of regenerative braking concept for electric vehicle enhanced with bidirectional converter," International Journal of Power Electronics and Drive Systems (IJPEDS), vol. 9, no. 4, pp. 1584-1590, 2018.

[4] N. Luo, J. Jiang, and A. Yu, "Research on the control strategy of the regenerative braking system," in 2014 International Conference on Mechatronics and Control (ICMC), 2014, pp. 2514-2517.

[5] Soeprapto, R. N. Hasanh, and Taufik, "Battery management system on electric bike using lithium-ion 18650," International Journal of Power Electronics and Drive Systems (IJPEDS), vol. 10, no. 3, 2019.

[6] R. Yazdanpanah and M. Mirsalim, "Hybrid Electromagnetic Brakes: Design and Performance Evaluation," IEEE Trans. Energy Convers., vol. 30, no. 1, pp. 60-69, Mar. 2015.

[7] Anon, "ICE3 pioneers commercial application of eddy-current rail brakes," Railw. Gaz. Int., vol. 156, no. 9, pp. 583-585, 2000.

[8] Ubaidillah, K. Hudha, and H. Jamaluddin, "Simulation and experimental evaluation on a skyhook policy-based fuzzy logic control for semi-active suspension system,” Int. J. Struct. Eng., vol. 2, 2011.

[9] M. Gulec, E. Yolacan, and M. Aydin, "Design, analysis and real time dynamic torque control of single-rotorsingle-stator axial flux eddy current brake," IET Electr. Power Appl., vol. 10, no. 9, pp. 869-876, Nov. 2016.

[10] A. Sinmaz, M. O. Gulbahce, and D. A. Kocabas, "Design and finite element analysis of a radial-flux salient-pole eddy current brake," in 2015 9th International Conference on Electrical and Electronics Engineering (ELECO), 2015, pp. 590-594.

[11] S. Cho; H. Liu;, H. W. Ahn; J. Lee; and H.-W. Lee, "Eddy Current Brake with a Two-Layer Structure: Calculation and Characterization of Braking Performance," IEEE Trans. Magn., vol. PP, no. 99, p. 5, 2017.

[12] T. Garbiec, M. Kowol, and J. Kołodziej, "Design considerations of high-speed eddy-current brake," Arch. Electr. Eng., vol. 63, no. 2, 2014.

[13] R. Yazdanpanah and M. Mirsalim, "Analytical study of axial-flux hybrid excitation eddy current brakes," Int. J. Appl. Electromagn. Mech., vol. 47, no. 4, pp. 885-896, 2015.

[14] J. Wang, H. Lin, and S. Fang, "Analytical Prediction of Torque Characteristics of Eddy Current Couplings Having

Int J Pow Elec \& Dri Syst Vol. 10, No. 4, Dec 2019 : 2198 - 2205 
a Quasi-Halbach Magnet Structure,” IEEE Trans. Magn., vol. 52, no. 6, pp. 1-9, Jun. 2016.

[15] X. Dai, J. Cao, Y. Long, Q. Liang, J. Mo, and S. Wang, "Analytical Modeling of an Eddy-current Adjustable-speed Coupling System with a Three-segment Halbach Magnet Array," Electr. Power Components Syst., vol. 43, no. 17, pp. 1891-1901, Oct. 2015.

[16] M. T. Thompson, "Practical Issues in theUse of NdFeB Permanent Magnets in Maglev, Motors, Bearings, and Eddy Current Brakes," 2009.

[17] G. L. Anantha Krishna and K. M. Sathish Kumar, "Investigation on Eddy Current Braking Systems - A Review," Appl. Mech. Mater., vol. 592-594, pp. 1089-1093, 2014.

[18] A. K. Singh, Ibraheem, and A. K. Sharma, "Parameter identification of eddy current braking sytem for various applications," in 2014 Innovative Applications of Computational Intelligence on Power, Energy and Controls with their impact on Humanity (CIPECH), 2014, pp. 191-195.

[19] W. R. Smythe, “On eddy currents in a rotating disk," Electr. Eng., vol. 61, no. 9, pp. 681-684, Sep. 1942.

[20] H. Waloyo, M. Nizam, D. Tiahiana, and Ubaidillah, "Parametric Design in Single Disk Axial Eddy Current Brake," in 2018 5th International Conference on Electric Vehicular Technology (ICEVT), 2018, pp. 132-135.

[21] M. Gulec and M. Aydin, "Modelling and Analysis of a New Axial Flux Permanent Magnet Biased Eddy Current Brake," 22nd International Conference on Electrical Machines, ICEM 2016. 2016.

[22] S. Sharif and K. Sharif, "Influence of skin effect on torque of cylindrical eddy current brake," in 2009 International Conference on Power Engineering, Energy and Electrical Drives, 2009, pp. 535-539.

[23] D. Schieber, "Unipolar induction braking of thin metal sheets," Proc. Inst. Electr. Eng., vol. 119, no. 10, p. 1499, 1972.

[24] A. Singh, "Theory of eddy-current brakes with thick rotating disc," Proc. Inst. Electr. Eng., vol. 124, no. 4, p. 373 , 1977.

[25] B. Lequesne, Buyun Liu, and T. W. Nehl, "Eddy-current machines with permanent magnets and solid rotors," IEEE Trans. Ind. Appl., vol. 33, no. 5, pp. 1289-1294, 1997.

[26] X. Dai, Q. Liang, J. Cao, Y. Long, J. Mo, and S. Wang, "Analytical Modeling of Axial-Flux Permanent Magnet Eddy Current Couplings With a Slotted Conductor Topology," IEEE Trans. Magn., vol. 52, no. 2, pp. 1-15, 2016.

[27] H. K. Razavi and M. U. Lampérth, "Eddy-Current Coupling With Slotted Conductor Disk," vol. 42, no. 3, pp. 405410, 2006.

[28] T. Lubin and A. Rezzoug, "3-D Analytical Model for Axial-Flux Eddy-Current Couplings and Brakes Under Steady-State Conditions," IEEE Trans. Magn., vol. VOL. 51, 2015.

[29] N. Labbe, Y. Marechal, G. Meunier, and H. B. Harara, "2D nonlinear finite element modelling of electromagnetic retarders using time-stepping algorithms, and the Petrov-Galerkin method with homogenization techniques," IEEE Trans. Magn., vol. 32, no. 3, pp. 772-775, May 1996.

[30] A. H. C. Gosline and V. Hayward, "Eddy Current Brakes for Haptic Interfaces: Design, Identification, and Control," 2008.

[31] K. Karakoc, E. J. Park, and A. Suleman, "Improved braking torque generation capacity of an eddy current brake with time varying magnetic fields: A numerical study," Finite Elem. Anal. Des., vol. 59, pp. 66-75, Oct. 2012.

[32] K. Karakoc, A. Suleman, and E. J. Park, "Optimized Braking Torque Generation Capacity of an Eddy Current Brake With the Application of Time-Varying Magnetic Fields," IEEE Trans. Veh. Technol., vol. 63, no. 4, pp. 1530-1538, May 2014.

[33] K. Karakoc, A. Suleman, and E. J. Park, "Analytical modeling of eddy current brakes with the application of time varying magnetic fields,” Appl. Math. Model., vol. 40, no. 2, pp. 1168-1179, Jan. 2016.

[34] M. Z. Baharom, M. Z. Nuawi, G. Priyandoko, and S. M. Harris, "Eddy current braking experiment using brake disc from aluminium series of A16061 and A17075," IOP Conf. Ser. Mater. Sci. Eng., vol. 36, p. 012005, Sep. 2012.

[35] W. K. A. Baran, "Influence of Different Magnetic Field Profiles on Eddy-Current Braking," IEEE Trans. Magn., vol. 6 , no. 2, pp. 260-263, 1970.

[36] M. O. Gulbahce, D. A. Kocabas, and F. Nayman, "Investigation of the effect of pole shape on braking torque for a low power eddy current brake by finite elements method," in 2013 8th International Conference on Electrical and Electronics Engineering (ELECO), 2013, no. 3, pp. 263-267.

[37] R. S. Robert, "2D model of axial-flux eddy current brakes with slotted conductive disk rotor," in 2017 International Siberian Conference on Control and Communications (SIBCON), 2017, pp. 1-6. 